\title{
Why It Matters For Collegial Leaders To Have A Binocular Vision
}

Prakash Singh, Nelson Mandela Metropolitan University, South Africa

\begin{abstract}
The question that is addressed in this article is whether it matters for collegial leaders to have a binocular vision. Imagine looking through a pair of binoculars as a metaphor for leadership. One lens of the binoculars represents cognitive abilities (IQ) and technical skills while the other represents emotional intelligence (EI). Monocular vision, using only IQ produces a very narrow view of the horizon. Binocular vision, combining IQ with EI, produces much clearer, broader and far reaching views. Exemplary collegial leaders use both lenses to inspire the best from their people and sustain high performance from individuals, teams and organizations. EI is not in opposition to IQ but it is an extension of the human's potential to succeed in a people-orientated environment. Traditional cognitive intelligence (IQ) is combined with non-cognitive intelligence (EI) to help leaders perform at their best and inspire their followers to be successful and happy. This exploratory research suggests that the complexities of organizations require a new focus on collegial leadership that extends beyond possessing cognitive abilities alone. The findings strongly suggest that a significant relationship exists between the development of a collegial environment that is identified by collaborative teamwork, shared decision-making, shared core values, a shared vision, shared leadership opportunities and meaningful empowerment, and a collegial leader's EI. The respondents' support for a leadership style that offers them the opportunity to be actively involved in creative decision-making strategies rather than be subjected to an autocratic style of control was clearly indicated in their responses.
\end{abstract}

Keywords: Collegial Leaders' Binocular Vision; Emotional Intelligence; Tobephobic Leaders; Employees’ Job Satisfaction Needs

\section{INTRODUCTION}

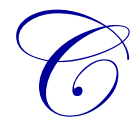

ollegiality is a collaborative process that entails the devolution of power to employees in order for them to become an integral part of the leadership process of the organization's shared vision (Cherniss, 2000; Singh, 2013a; 2013b). Collegial leaders understand that only when their constituents feel strong, capable, and efficacious, and when they feel connected with one another, can they ever hope to get extraordinary things done (Kouzes \& Posner, 2001). Collegial leaders devote much of their time and effort building sound relationships with their employees based on mutual respect and caring. In addition to having the prerequisite cognitive abilities (IQ) and technical skills for their positions, collegial leaders are equally required to demonstrate high levels of EI and collegiality in their working environment (Singh, 2013b). EI is not in opposition to IQ, but according to Stein and Book (2001), it is an extension of the human's potential to succeed in a people-orientated environment. It is also affirmed by researchers such as Stein and Book (2001) and Goleman (1998) that EI is not the antithesis of IQ, but rather, it is a combination of both emotion and cognition. EI has increasingly become a vital part of how today's leaders meet the significant challenges they face (Childs, 2004; Singh, 2013b). As Fullan (2001) justly points out, the culture of change in many organizations is rife with anxiety, stress and ambiguity and therefore, it should come as no surprise then that the most effective leaders are not the smartest in an IQ sense but are those who combine intellectual brilliance with emotional intelligence. In 1980, Reuven Bar-On investigated the qualities that led to success and he showed that there was much more than the traditional Intelligence or IQ that was associated with an individual's success and Bar-On consequently developed the concept of Emotional Intelligence the Emotional Quotient or EQ was born (Childs, 2004). 
Broadly defined, EI addresses the emotional, personal, social, and survival dimensions of intelligence (Singh, 2013b; Dantley, 2005). EI and emotional skills develop over time, change throughout life, and relate to one's potential for performance, are process-oriented, and can be improved through training (Mayer \& Salovey, 1997; Singh, Manser \& Dali, 2013). EI is not a replacement for on the job skills and intelligent, task-related, logical thinking, but it adds to the variety of skills that empower leaders to develop workers through the enhancement of their collegial leadership skills (Caruso \& Salovey, 2003). As pointed out by Goleman (1998), the importance of EI lies in the fact that there are certain situations specifically in the areas of leadership where EI could be more effective than IQ in terms of personal communication, motivation, self-control and empathetic behaviour. In other words there are emotional factors that are not IQ related that play a relatively greater role in the acquisition of more favourable outcomes in the workplace when related specifically to relationships. Also, Bazerghi (2003a) avers that traditional cognitive intelligence (IQ) is combined with non-cognitive intelligence (EI) to help leaders perform at their best and inspire their followers to be successful and happy. According to Bazerghi (2003b), this means that combining these two competencies could form the foundation for leadership effectiveness, inspirational workers, high levels of achievement and ultimate job satisfaction. Therefore, the question that is addressed in this exploratory study is whether it matters for collegial leaders to have a binocular vision in addressing the job satisfaction needs of their workers in their organizations. The creation of a functional collegial work environment is part of this investigation since it would evoke the attributes of ideal collegial leaders.

\section{A BINOCULAR VISION OF COLLEGIAL LEADERSHIP}

Collegial leadership must be viewed as a process that encourages and accommodates shared decisionmaking and shared leadership in the spirit of enabling people to want to act (Kouzes \& Posner, 1997; Singh, 2013a). Emotionally intelligent leaders experience a greater sense of well-being, improved relationships, happier employees and lower employee turnover, better teamwork, greater job satisfaction and a greater degree of business success (Thilo, 2004; Singh, 2013c; Singh, Manser \& Mestry, 2007). Emotional intelligence is regarded as one of the most important factors in achieving success, seeing that high levels of achievement, success, and happiness are selfdefined and directed (Merkowitz \& Earnest, 2006). Research (Sternberg, 1996; Goleman, 1998; Caruso \& Salovey, 2003; Manser, 2005; Singh, 2010) alludes to social and emotional abilities being of greater importance than IQ in determining leadership success. Imagine a leader looking through a pair of binoculars as a metaphor for leadership. One lens of the binoculars represents IQ while the other represents EI. Monocular vision of leaders, using only IQ, produces a very narrow view of the horizon. On the other hand, leaders making use of a binocular vision, combining IQ with EI, produce much clearer, broader and far reaching views of their organizations. Exemplary collegial leaders would use both lenses to inspire the best from their people and sustain high performance from individuals, teams and organizations (Human Performance Strategies, 2006).

According to Childs (2004), leadership has had to evolve to match a growing sense of democracy and independence in the workforce, and employees now have far more options and choices than the "foot soldiers of yesterday". Leaders now need to manage and lead an empowered workforce and go beyond the consultative, cooperative and democratic styles of today. These new demands include (Childs, 2004):

- $\quad$ Consultation and involvement - but leaders still get criticised for not having nor communicating a compelling vision and purpose;

- $\quad$ Autonomy and freedom - but leaders are still expected to take full responsibility when things go wrong;

- Opportunities for growth, challenge and glory - but leaders must be on hand to coach and mentor employees so that they develop their potential;

- Inclusion and team spirit - but employees still want their leaders to give them individual recognition and acknowledgement.

Goleman (2004, p. 4) points out that "when it comes to shaping our decisions and our actions, feeling counts every bit as much as - and often more than - thought." He believes that we "have gone too far in emphasizing the value and import of the purely rational - of what IQ measures - in human life. Intelligence can come to nothing when the emotions hold sway." In a study that examined how leaders of various personality types value and develop EI, Richmond, Rollin and Brown (2004) found that emotional intelligence attributes such as vision, relationship building and people development are essential to successful leadership. Additional attributes such as teamwork, 
initiative, achievement drive, optimism and empathy were also high on the list of priorities defining leadership. The 265 leaders who participated in this research internationally, ranked the emotionally intelligent competencies higher than the general leadership abilities such as planning and financial management.

Belasco and Stayer (1993) suggest four responsibilities a leader must implement at all levels of an organization. First, transfer ownership for work to the people who do the work. Second, create the environment where the transfer of ownership can take place, where each person wants to be responsible for his or her own performance. This entails painting a clear picture of what the organization believes great performance is for the organization and each person; focusing individuals on the few great performance factors; developing in each person the desire to be responsible for his or her performance; aligning organization systems and structures to send a clear message as to what is necessary for great performance; engaging each individual's heart, mind and hands in the business of the organization; and energizing people around the organization's focus. Third, develop individual capability and competence. Fourth, create conditions in the organization that challenge every person to continually learn. These four principles align personal and organizational goals with the emotionally intelligent competencies of collegial leaders.

Saarni (2000) points out that competence has a history in Western psychology as referring to one's mastery of some skill yet one need not necessarily reliably perform the skill because performance depends heavily on circumstances and incentives. Bliss (2006) believes that EI is a combination of competencies. These skills contribute to a person's ability to manage and monitor his or her own emotions, to correctly gauge the emotional state of others and to influence opinions (Goleman, 1998). Goleman describes a model of five dimensions, namely: self-awareness, self-management or self-regulation, motivation, empathy and social skills. As pointed out by Bliss (2006), social skills are fundamental to emotional intelligence. They include the ability to induce desirable responses in others by using effective diplomacy to persuade (influence); listen openly and send convincing messages (communicate); inspire and guide groups and individuals (leadership); nurture instrumental relationships (building bonds); work with others toward a shared goal (collaboration, cooperation); and create group synergy in pursuing collective goals. In order for employees to reach a level of job satisfaction that produces high levels of efficiency and effectiveness, leaders need to demonstrate very specific emotionally intelligent behaviours (EIBs) and leadership skills (Gardner \& Stough, 2002):

The ability of the leader to be able to identify and understand the emotions of others in the workplace, to be able to manage their own and others' positive and negative emotions, to be able to control emotions in the workplace effectively, to utilise emotional information when problem solving and to be able to express their feelings to others is integral to the leader being effective at creating appropriate levels of job satisfaction. (p. 76)

All leaders are expected to share some common traits (Bliss, 2006). The first is a guiding vision or purpose. Leaders who have a clear idea of what they want to do professionally and personally will pursue the goal regardless of the setbacks. The second characteristic is passion or enthusiasm and the ability to communicate that passion to others. Third is integrity, consisting of three ingredients: self-knowledge, candour and maturity. Self-knowledge is knowing one's strengths and weaknesses. Candour is being honest with yourself and is the key to knowing yourself. Maturity is the result of the lessons learned through following, while observing others, learning to be dedicated, and working with others. It is being truthful and never servile. The last two traits go hand in hand: curiosity and daring. A leader wants to learn as much as possible and is willing to take risks (Bush, 1995). Bliss (2006) supports the notion that a leader has to have EI to align personal and subordinate goals to accomplish organizational goals. As pointed out by Kouzes and Posner (1997, p. 12), leaders "know that no one does his or her best when feeling weak, incompetent, or alienated; they know that those who are expected to produce the results must feel a sense of ownership."

Recent studies cited therefore confirm that collegial leadership not only involves leadership behaviours that build willing followers who commit themselves to the organization's objectives, but it also empowers followers to accomplish these objectives by their becoming leaders in their own fields of expertise (Kouzes \& Posner, 1997; Yukl, 1998; Goleman, 1996; Singh, 2013b). Enabling or empowering employees therefore is an important aspect in establishing emotionally intelligent collaboration, as the willing and satisfied participation of the employees can be 
the result of leaders' commitment to establishing a collegial working environment as demonstrated by their EIBs (Manser, 2005; Singh, 2013c; Singh, Manser \& Dali, 2013).

\section{TOBEPHOBIC LEADERSHIP: FLIP SIDE OF COLLEGIALITY?}

As affirmed by Kouzes and Posner (1997, p. 16), traditional "management teachings suggest that the job of management is primarily one of control: the control of resources, including time, materials, and people." They point out that leaders "don't command and control; they serve and support." Collegial leaders can be classified as emancipators seeing that they contribute extensively to creating a working environment for emancipation (Singh, 2013a). Collegial leadership is characterized by devolution of power by leaders to their employees (Singh, 2013a). Recent research studies strongly suggest that the flip side of collegial leadership is tobephobic leadership (Singh 2013a; 2013c; 2013d). In the latter situation, traditional bureaucratic management strategies create minimal opportunities for employees to be part of the normal decision-making process in organisations.

The cost-effectiveness of EI is a relatively new and innovative approach many traditional managers may find it difficult to accept. Goleman's (1996) study of 250 executives found that most felt their work demanded "their heads but not their hearts" (p. 149). Many executives in the latter study said that they feared that expressing empathy towards their employees would place them in conflict with their organizational goals. Even nowadays, such tobephobic leaders lack a binocular vision in their relationship with their workers (Singh, 2013a). The empowerment of employees in any organization would depend to a great extent on the devolution of power by their leaders. However, traditional managers cling to power as an entitlement of their positions. In contrast, collegial leaders would share their power base in order to flatten hierarchies in their organisations (Kouzes \& Posner, 1997). Empowered employees would therefore demonstrate a greater commitment to complete a task based on their increased sense of self-confidence, self-determination and personal effectiveness (Singh, 2013a; 2013d). EI is almost wholly responsible for the superior performance in leadership roles and when one is asked to consider what makes memorable leaders so special, one's response may correspond with their level of EI (Goleman, 1996). Such leaders may be described as showing emotional competence because of their ability to utilise their EI effectively.

Tobephobic leaders insist on employing autocratic approaches in their organizations. A leader does not simply wear a hat associated with a specific position or perform the functions associated with the job description in a technocratic and bureaucratic manner. This approach is usually associated with the functions of a bureaucratic manager. Collegial leaders wear many hats and consequently assume several roles, and depending on the task situation they find themselves in, they can be leaders or subordinates, depending on the circumstances that prevail in the organisation (Kochan \& Reed, 2005; Singh, 2005; Thilo, 2004; Kouzes \& Posner, 1997). Credible leaders prefer to give away their power in the service of others and for a purpose larger than themselves (Kouzes \& Posner, 1997). Such leaders accept and act on the paradox of power: we become the most powerful when we give our own power away (Kouzes \& Posner, 1997). Collegial leaders take the power that flows to them and connect it to the other members of their team. As pointed out by Kouzes and Posner (1997), when leaders share power with others, they are demonstrating profound trust in and respect for the other's abilities. Such leaders accept and act on the paradox of power: we become the most powerful when we give our own power away. Such leaders are most respected and most effective, not as traditional management myth has it - the highly controlling, tough-guy boss - as is characterized by tobephobic leaders who demonstrate the following traits (Singh, 2013a; 2013c; 2013d):

- $\quad$ They demonstrate low levels of EI and collegiality and are autocratic in decision-making.

- They do not inspire or motivate others. There is little or no encouragement given to employees and interpersonal contact is kept to a minimum.

- $\quad$ They are difficult to talk to, and they don't seem to listen. They are often preoccupied and as a result they are poor communicators.

- $\quad$ They are guilty of throwing tantrums and can be bad-tempered.

- $\quad$ They show little or no compassion and therefore treat fellow workers shabbily.

- $\quad$ They experience difficulties in establishing healthy relationships within the working environment.

- $\quad$ They do not overtly and willingly regard the happiness and job satisfaction needs of their employees as a priority. 
Research (Northouse, 2004) strongly supports the notion that a leader requires a high level of EI in addition to IQ to achieve the goals of the organization. On the other hand, traditional managers require cognitive abilities and technical skills to get the work done by their employees. This does not imply that management is not important in organizations. However, the approach of managers becomes highly critical when the focus is purely task orientated. As pointed out by Northouse (2004), to manage means to accomplish activities and master routines while to lead means to influence others and create visions for change. Researchers argue that managers and leaders are different types of people, managers being more reactive and less emotionally involved, and leaders being more proactive and more emotionally involved. Education and learning require the perspective of balance between academic achievement and becoming emotionally intelligent. EI can help leaders in an increasingly difficult leadership role, and in the middle of the "Talent War", especially at the highest levels in organisations, emotional intelligence can give developing leaders a competitive edge (Childs, 2004). In their work with EI, Merkowitz and Earnest (2006) have personally seen individuals improve their leadership capacities and skills in their professional role and enhance their personal lives. As pointed out by Kochan and Reed (2005), an ideal learning community is organized in a way that fosters an open flow of thoughts; stimulates critical reflection about analyses of ideas, policies, problems, and solutions; creates notions of what is universally acceptable as being the common good and develops a concern for the rights and dignity of all people.

\section{SUPPORTING RESEARCH}

It's impossible to construe collegial leadership traits without focusing on EI. EI begets collegial leadership and this comes out clearly in the discussion below, based on the research findings of this exploratory study. The findings of the study are used in this paper to focus largely on developing a conceptual framework for emotionally intelligent collegial leaders (Collegial Leadership Grid) as a major recommendation emanating from the research undertaken.

\section{Synopsis of Research Findings}

Using purposeful sampling, four hundred and seventy four respondents were selected to participate in this quantitative study. A structured questionnaire was completed by the employees to determine their perceptions of their leaders' intrapersonal and interpersonal emotionally intelligent behaviours (EIBS). The interpersonal EIBs in this study are: leadership, communication, empathy, trust, conflict management, and relationships. The intrapersonal EIBs are: self-awareness, self-confidence, self-control, self-expression, adaptability, and optimism. The findings strongly suggest that a significant relationship exists between the development of a collegial environment that is identified by collaborative teamwork, shared decision-making, shared core values, a shared vision, shared leadership opportunities and meaningful empowerment and a collegial leader's EIBs. The respondents' support for a leadership style that offers them the opportunity to be actively involved in creative decision-making strategies rather than be subjected to an autocratic style of control was clearly indicated in their responses.

The link between collegiality and meaningful interpersonal and intrapersonal EIBs is significant and directly related to a sense of job satisfaction amongst all employees. Furthermore, the responses indicated that workers have expectations of empowerment and collaboration that would enhance their level of job satisfaction and these expectations are supported by their belief that they would feel satisfied if their leaders gave them the opportunity to develop their skills in an environment that nurtures effective communication, healthy relationships, empathy and trust. In order to be satisfied, the findings clearly indicate that employees need to be led by leaders who are confident and not tobephobic in their leadership role; who send out clear unambiguous messages; who maintain self-control; who are adaptable and flexible; who believe in shared leadership and who face the future with optimism.

\section{A Functional Collegial Environment}

In terms of the findings of this study, a functional collegial environment is apparent when the six foundations of collegiality underpin the core purpose of the organization. According to Singh and Manser (2002), and Singh (2005), there are six underlying principles or foundations that determine whether a collegial environment exists in organizations, and these foundations are: accountability, shared core values, shared vision, shared decision- 
making, shared leadership, and empowerment. Accountability is shared and employees are happy to be held accountable for leadership roles that they have chosen. There is shared empowerment and shared leadership, which indicate that employees have been given the opportunity to take on leadership roles and be accountable for decisions that they make without the interference of those in more powerful hierarchical positions. On the other hand, a nonfunctional collegial working environment could indicate that the leader does not fully support or understand the concept of collegiality. Opportunities for shared accountability may exist but the leader is reluctant to empower employees and share leadership roles.

\section{A Non-Existent Collegial Environment}

In terms of the findings of this study, a non-existent collegial environment could suggest two scenarios that can be described as being opposite to a functional collegial environment. The first one depicts a leadership structure that is largely autocratic. Accountability is not shared; leadership is regarded as a position of pre-ordained hierarchical power and the tobephobic leaders by choice hold themselves accountable for all that happens in their organizations. They determine the core values and their organizations' vision (if it exists) and the workers are told to abide by them. The focus is on getting the job done in the most efficient way possible regardless of personal sacrifices that will need to be made. It is a cold, impersonal well-oiled machine. The second scenario depicts a sense of disarray and chaos in the organization. There is a very poor or non-existent work ethic. Workers are unsure of what the requirements of the organization are, and have lost faith in their leader's ability to lead. There is a high rate of employee absenteeism, productivity is poor and the organisation is clearly rudderless. There are no core values in place, there is no vision for the organization and empowerment amplifies feelings of desperation to get things done by the few committed employees that may be present.

\section{Demonstration of Appropriate EIBs by Collegial Leaders}

The findings in this study therefore suggest that the presence of appropriate EIBs in the leadership structure of the organizations denote the following:

- $\quad$ The leaders make use of appropriate collegial leadership strategies and they know their workers well.

- $\quad$ They communicate effectively and they are able to manage conflict situations.

- $\quad$ They build healthy relationships based on trust with their employees.

- They show compassion and understanding through their demonstration of empathy and they are trustworthy and sincere.

- $\quad$ They are able to recognize their own strengths and weaknesses through their own self-awareness.

- $\quad$ They are confident in their roles as leaders and their feelings are clearly recognizable.

- They are in control of their emotions and they do not vacillate between emotional extremes.

- $\quad$ They are adaptable and flexible in their thinking and actions and they remain optimistic.

In contrast, tobephobic leaders do not handle conflict well, will not ask for help and will not apologise if in the wrong. Relationships are avoided and they do not seem to be concerned with others' problems. It seems as if they doubt the abilities of their employees and therefore constantly supervise them. There seems to be a mutual feeling of distrust. They do not seem to understand their workers' job satisfaction needs very well and as a result do not show empathy towards them. Such leaders lacking appropriate EIBs do not inspire confidence and cannot be relied upon to serve the best interests of the organization in the face of adversity. There are often examples of erratic behaviour and noticeable mood-swings and they are sometimes unpredictable and irrational. Clearly a collegial leader who demonstrates appropriate levels of EIBs will either create a functional collegial working environment or thrive in one. A functional collegial working environment will be nurtured under the leadership of a leader who displays appropriate EIBs. Evidently, functional collegial environments and appropriate levels of leaders' EIBs contribute significantly to the job satisfaction of employees.

\section{The EIB Job Satisfaction Grid}

The findings of the study further suggest that a leader's ability to display predictable and appropriate interpersonal and intrapersonal EIBs can be described as a process that does more than positively influence the job 
satisfaction of employees. It also allows employees to understand their leaders more and makes them feel more at ease because they know how their leaders will behave or react and that the EIBs demonstrated will be appropriate and acceptable. Also, leaders become more aware of how they will act and react and therefore they begin to learn more about themselves. The EIB job satisfaction grid (Figure 2) outlines this clearly. The EIB job satisfaction grid is based on an extension of the original Johari grid (see Figure 1) that was designed by Hersey and Blanchard (Van der Westhuizen, 1991).

The Johari grid represents the relationship between leaders and their employees. The four quadrants of the grid represent the following:

- $\quad$ Quadrant 1: Certain behaviours are known to the leaders and are observed by their employees. The leaders' intentions and actions are clear and they are observed and understood by others.

- $\quad$ Quadrant 2: Others observe the leaders' behaviours of which they are unaware.

- $\quad$ Quadrant 3: There are behaviours of the leaders that go by unnoticed by everyone.

- $\quad$ Quadrant 4: There are feelings that the leaders have of which others are unaware.

The ideal situation is that the known quadrant (1) should extend as indicated by the arrows (Figure 1) and that the other three quadrants should become smaller and smaller until a situation develops in which everyone knows what to expect from the leaders in different situations. The leaders would therefore also be able to predict how they would react or what they would do and if the subordinates seldom knew what to expect, then this could lead to uncertainty. This model is unsuitable for the prediction of job satisfaction, as the leaders' EIBs need to be both appropriate and predictable; therefore it needs to be modified to accommodate this requirement. To merely understand or expect a certain type of behaviour from one's leader may do little to improve one's feeling of job satisfaction. The behaviours although predictable may be inappropriate and the inappropriateness of the leader's behaviour may create a sense of dissatisfaction. A leader's predictable but inappropriate behaviour may be debilitating and restrictive rather than beneficial. Employees may be fearful and feel demotivated and dissatisfied if their leader's predictable behaviour is often perceived as being inappropriate.

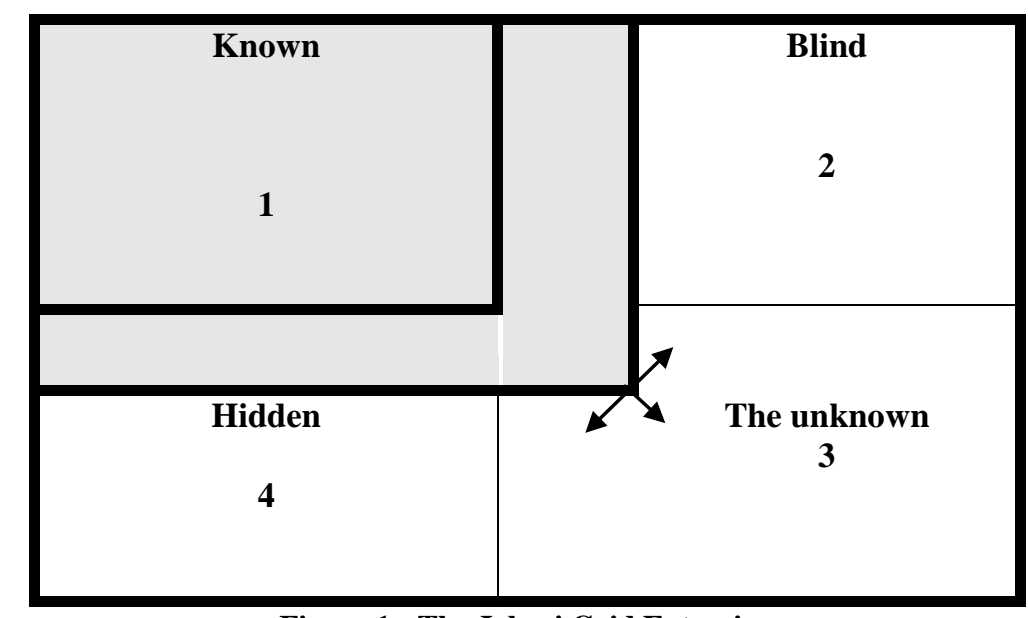

Figure 1: The Johari Grid Extension

The Johari Grid is therefore further adapted to accommodate the observable EIBs that a leader should demonstrate in order for employees to experience a sense of job satisfaction. This (EIB) grid (Figure 2) no longer refers to general behaviours but refers specifically to the EIBs that have been identified in this study. They comprise the six interpersonal EIBs (leadership, communication, conflict management, relationships, empathy, and trust) and six intrapersonal EIBs (self-awareness, confidence, self-expression, self-control, adaptability, and optimism). The adapted grid is entitled the EIB job satisfaction grid and is presented in Figure 2. The grid is explained as follows:

- $\quad$ Quadrant 1: The leader displays appropriate interpersonal and intrapersonal EIBs that suit the situation and the individual. The employees are aware that the leader will behave and act appropriately. In other words 
the leader's intentions and behaviours are clear and they are observed and accepted by others as being emotionally intelligent and appropriate. This quadrant represents a functional collegial environment that will enhance an employee's sense of job satisfaction.

- Quadrant 2: The leader displays inappropriate interpersonal EIBs that do not suit the situation or the individual. The employees are not aware that the leader will behave and act appropriately. In other words, although the leader's intentions and actions are clear they are observed and accepted by others as being inappropriate and lacking EI. According to the findings of this study, this quadrant will bring about job dissatisfaction for the employees.

- $\quad$ Quadrant 3: The employees do not know what to expect from the leader. They do not know what emotions will be displayed and they do not know whether they will be appropriate EIBs or not. This is the uncertain, unknown zone, which promotes a sense of job dissatisfaction amongst workers.

- $\quad$ Quadrant 4: The leader displays inappropriate intrapersonal EIBs that should not be forthcoming from a leader. The employees are not aware that the leader will behave and act appropriately. In other words, although the leader's intentions and actions are clear, they are observed and accepted by others as being inappropriate and lacking EI. According to the research findings, this quadrant will also bring about job dissatisfaction.

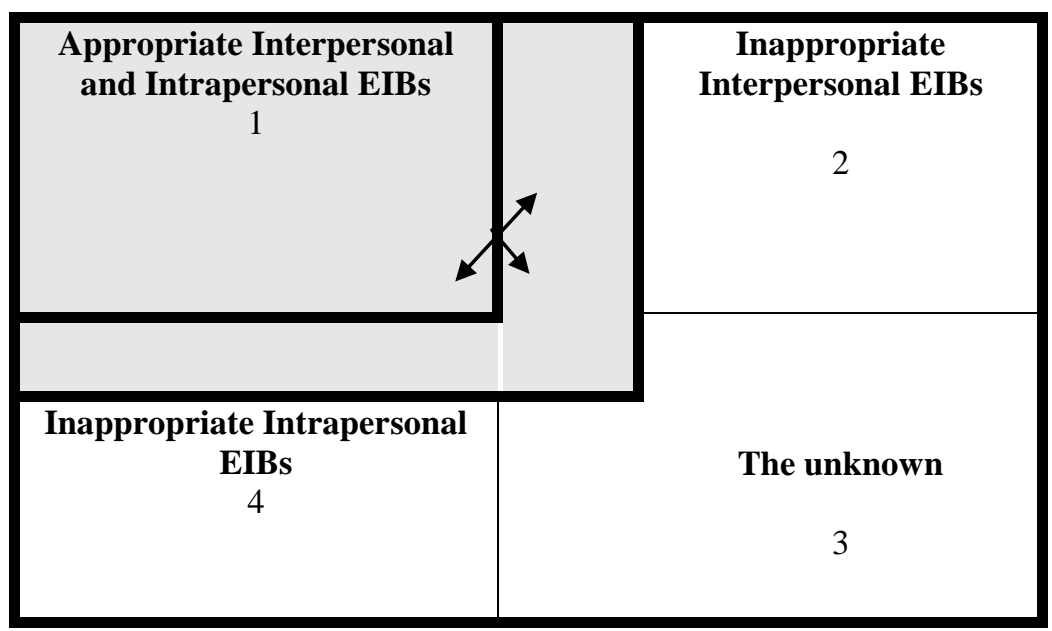

Figure 2: The EIB Job Satisfaction Grid

The ideal situation is that leaders become more emotionally intelligent in that they demonstrate appropriate interpersonal and intrapersonal EIBs. Quadrant 1 should therefore extend as shown by the arrows in Figure 2 and the other three quadrants should become smaller and smaller until a situation develops in which employees know that the leaders' EIBs will be appropriate. The findings reveal that in such a situation, employees experience a sense of confidence, interest, achievement and job satisfaction. This will create organizations where all employees will know that their leaders' EIBs will be appropriate, that a functional collegial environment will be established and that there will be a sense of job satisfaction that abounds in their working environment.

Evidently, the research findings denote that a personal and emotional accountability system is essential for positive human development within the working environment. Unchecked emotional stress, ineffective and poor relationships, and personal stagnation can be costly in terms of human resource development. Honest selfassessment by leaders is requisite to positive and intentional personal change. Self-awareness is an essential attribute of any leader seeing that it is the ability to recognize a feeling as it happens, to accurately perform self-assessments and have self-confidence. It is the keystone of emotional intelligence (Goleman, 2004). Self-management or selfregulation on the other hand, is the leader's ability to keep disruptive emotions and impulses in check (self-control), maintain standards of honesty and integrity (trustworthiness), take responsibility for one's performance (conscientiousness), handle change (adaptability), and be comfortable with novel ideas and approaches (innovation). Motivation is the emotional tendency guiding or facilitating the attainment of goals shared by leaders with their followers (Bliss, 2006). It consists of achievement drive (meeting a standard of excellence), commitment (alignment 
of goals with the group or organization), initiative (acting on opportunities), and optimism (persistence reaching goals despite set backs). Leaders cannot function without empathy seeing that it is the understanding of others by being aware of their needs, perspectives, feelings, concerns, and sensing the developmental needs of others (Goleman, 1998; Bliss, 2006; Kouzes \& Posner, 1997; Northouse 2004).

\section{COLLEGIAL LEADERSHIP GRID}

Based on the research findings, the Collegial Leadership Grid (CLG) was developed. The CLG in Figure 3 depicts the relationship between collegiality and the perceived EI of leaders. The main characteristics of the CLG are the following:

\section{Ineffectual Collegial Leaders}

Despite having a satisfactory relationship with their workers, such leaders create very few opportunities for them to assume shared leadership roles. A bureaucratic-bossy approach is evident in such an environment. Although these leaders are able to recognize their strengths, they do not hesitate to spell out the expectations of the organization without affording the staff the opportunity to participate jointly in the decision-making process. Workers are not empowered to share the vision of the organization and consequently, a feeling of despondency amongst them can set in resulting in job dissatisfaction.

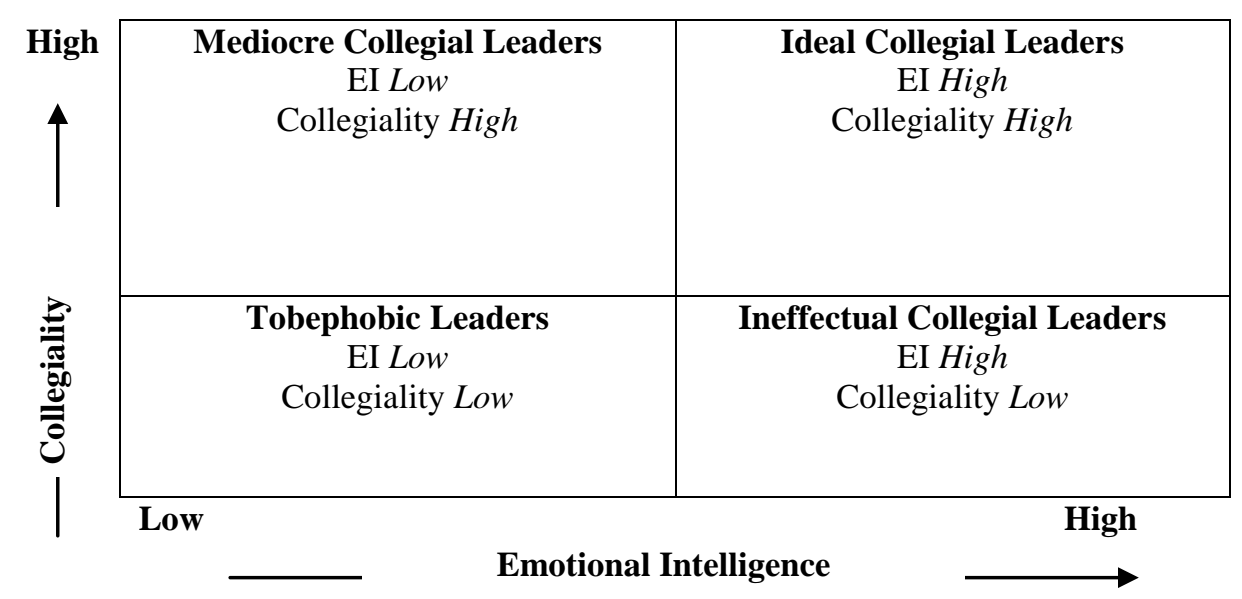

Figure 3: Collegial Leadership Grid

\section{Tobephobic Leaders}

Tobephobic leaders demonstrate low levels of both EI and collegiality and prefer being autocratic in managing their organizations. They easily throw tantrums and can be bad-tempered. They do not show compassion and therefore treat their employees shabbily. These leaders tend to experience difficulties in establishing healthy relationships with their employees and have limited preference for shared decision-making. Happiness and job satisfaction can become a challenge for employees to attain in such a non-existent collegial environment.

\section{Mediocre Collegial Leaders}

Having a lower EI, such leaders do not appear to be optimistic at all times. They are not always in control of their emotions despite creating limited opportunities for shared leadership roles within their organizations. Ambiguity and uncertainty can cloud the positive intentions of such mediocre leaders who have ambiguous intentions to create a functional collegial environment in the organizations. Job satisfaction could evade workers whose leaders are low on EI even though they demonstrate some scattered traits of collegiality. 


\section{Ideal Collegial Leaders}

Such leaders demonstrate high levels of both EI and collegiality in the environment. Empathy, empowerment and emancipation underpin joint decision-making and shared leadership in this highly functional collegial environment. Ideal collegial leaders are imbued with personal and social skills which they employ to contribute to the job satisfaction of their fellow workers in the environment. Integral to the success and development of the collegial process is that employees are happy and motivated in a functional collegial environment, and they feel that they are being nurtured in an open, warm and sincere environment.

Research (Northouse, 2004) strongly supports the notion that a leader requires a high level of EI in addition to IQ to achieve the goals and vision of the organization. According to Manz and Sims (2001:68-69), a fundamental reason for shifting employees from dependence to independence "is to improve bottom-line indicators such as productivity and quality while the follower benefits as well. Clearly, this would not be possible unless every employee was considered a true self-leader." Being a leader requires the person to promote an organizational passion for quality. The CLG strongly suggests that there should be a strong relationship between EI and collegiality as part of a collegial leader's binocular vision. Such a leadership style emphasizes empowerment rather than dependence (Gardner \& Stough, 2002). Goleman (1998) suggests that people's emotions do matter and if they are ignored, quality performances will diminish. Empathetic leaders care about their workers and show interest in and concern for them by "tuning in" as to what, how and why they feel and think the way they do (Stein \& Book, 2001). Above all, if there is a leader who is a bastion of controlled emotion, then the evidence suggests that it helps employees feel happy and satisfied at work (Singh, Manser \& Dali, 2013).

\section{CONCLUSION}

Evidently, a functional work environment needs to be galvanized by a satisfied and emotionally contented workforce. Being a collegial leader would require such a person to promote an organizational passion that identifies and acknowledges the contribution of every employee. Collegiality is about sharing responsibilities and being accountable for one's actions. Leaders must therefore be equipped with the knowledge, skills, abilities, beliefs, and dispositions that will allow them to succeed in their organizations. These abilities should not only dwell on cognition alone but also, equally, on the development of their emotional intelligence. It is therefore a myth that leaders are entrusted with absolute power to manage all the resources of their organizations. Workers feel confident with leaders who are adaptable, flexible and supportive when it comes to shared decision-making and the devolution of power within the organization. Furthermore, the leaders' sense of optimism is a source of inspiration for those around them and it sets the tone for the way that employees feel about their place of work. This exploratory study therefore explains why it matters for collegial leaders to have a binocular vision. More research needs to be done on the binocular traits of collegial leaders. Liberate the collegial leader in every worker, and extraordinary things can transpire in any organization!

\section{AUTHOR INFORMATION}

Prakash Singh is a professor of education at the Nelson Mandela Metropolitan University in Port Elizabeth, South Africa. He is currently a rated researcher by the National Research Foundation in South Africa, and is a former Senior Research Fulbright scholar. Professor Singh is the author of Innovative Strategies to Develop Better Schools and co-author of Principal Leadership. He has also published widely in peer-reviewed journals, focusing on collegial leadership, traditional bureaucratic management practices, organizational effectiveness, emotional intelligence, tobephobia, and self-regulated learning. Professor Singh has presented numerous papers at international conferences. E-mail: Prakash.Singh@nmmu.ac.za

\section{REFERENCES}

1. Bazerghi, E. (2003a). Emotionally intelligent leadership. Retrieved from: www.humanperformancestrategies.com

2. Bazerghi, E. (2003b). Organizational effectiveness. Retrieved from: www.humanperformancestrategies.com 
3. Belasco, J.A. \& Stayer, R.C. (1993). Flight of the buffalo: Soaring to excellence, learning to let employees lead. New York: Warner.

4. Bliss, S.E. (2006). The effect of emotional intelligence on a modern organizational leader's ability to make effective decisions. Retrieved from: http://eqi.org/mgtpaper.htm

5. Bush, T. (1995). Theories of educational management. London: Paul Chapman.

6. Caruso, D. \& Salovey, P. (2003). The emotionally intelligent manager. San Fransisco: Jossey-Bass.

7. Cherniss, C. (2000). Social and emotional competence in the workplace. In R. Bar-On \& J.D.A. Parker (Eds.), The handbook of emotional intelligence. San Francisco: Jossey-Bass.

8. $\quad$ Childs, R. (2004). Emotional intelligence and leadership. Retrieved from: http://www.teamtechnology.co.uk/emotional-intelligence.html

9. Dantley, M.E. (2005). Moral leadership: Shifting the management paradigm. In F.W. English (Ed.), The Sage handbook of educational leadership. London: Sage.

10. Fullan, M. (2001). Leading in a culture of change. Retrieved from:http://administration.ucok.edu/booksummaries/pdf/LeadinginaCultureofChange.pdf

11. Gardner, L. \& Stough, C. (2002). Examining the relationship between leadership and emotional intelligence in senior level managers. Leadership and Organisation Development Journal, 23: 68-78.

12. Goleman, D. (1996). Emotional intelligence. London: Bloomsbury.

13. Goleman, D. (1998). Working with emotional intelligence. New York: Bantam Books.

14. Goleman, D. (2004). Emotional intelligence \& working with emotional intelligence. London: Bloomsbury.

15. Human Performance Strategies. (2006). Emotional intelligence. Retrieved from: http://humanperformancestrategies.com/ei.htm

16. Kochan, F.K. \& Reed, C.J. (2005). Collaborative leadership, community building, and democracy inpublic education. In W.E. Fenwick (Ed.), The Sage handbook of educational leadership. London: Sage.

17. Kouzes, J.M. \& Posner, B.Z. (1997). The leadership challenge. San Francisco: Jossey-Bass.

18. Kouzes, J.M. \& Posner, B.Z. (2001). Bringing leadership lessons from the past into the future. In W. Bennis, G.M. Spreitzer \& T.G.Cummings (Eds.), The future of leadership. San Francisco: Jossey-Bass.

19. Manser, P.G. (2005). The influence of school principals' emotionally intelligent behaviours on the job satisfaction of educators in the Eastern Cape. (Unpublished PhD thesis). Port Elizabeth: Nelson Mandela Metropolitan University.

20. Manz, C.C. \& Sims, H.P. (2001). The new super leadership. San Francisco: Berrett-Koehler.

21. Mayer, J.D. \& Salovey, P. (1997). What is emotional intelligence. In P. Salovey \& D. Sluyter (Eds.), Emotional development and emotional intelligence. New York: Basic Books.

22. Merkowitz, R.F. \& Earnest, G.W. (2006). Emotional intelligence: A pathway to self-understanding and improved leadership capacities. Retrieved from: http://www.joe.org/joe/2006august/iw3.shtml

23. Northouse, P.G. (2004). Leadership: theory and practice. London: Sage.

24. Richmond, S.L., Rollin, P.F. \& Brown, J.M. (2004). What makes a successful leader. Retrieved from: http://www.ideashape.com/documents/what-makes-a-successful-leader-report.pdf

25. Saarni, C. (2000). Emotional competence: A developmental perspective. In R. Bar-On \& J.D.A Parker (Eds.), The handbook of emotional intelligence. San Francisco: Jossey - Bass.

26. Singh, P. (2005). Use of the collegial leadership model of emancipation to transform traditional management practices in secondary schools. South African Journal of Education, 25(1): 11-18.

27. Singh, P. (2010). Innovative strategies to develop better schools. Sydney, Australia: Common Ground.

28. Singh, P. (2013a).Transforming traditional bureaucratic management practices by employing the Collegial Leadership Model of Emancipation. International Business and Economics Research Journal, 12(8): 953968.

29. Singh, P. (2013b). Influence of the leaders' emotionally intelligent behaviours on their employees' job satisfaction. International Business and Economics Research Journal, 12(7): 799-814.

30. Singh, P. (2013c). A collegial approach in understanding leadership as a social skill. International Business and Economics Research Journal, 12(5): 489-502.

31. Singh, P. (2013d). Influence of leaders' intrapersonal competencies on employee job satisfaction. International Business and Economics Research Journal, 12(10): 1289-1302.

32. Singh P. \& Manser P. (2002). Collegiality in education: a case study. South African Journal of Education, 22(1): 56-64. 
33. Singh, P., Manser, P. \& Dali, C. (2013). Principal leadership. Saarbrucken, Germany: LAP LAMBERT Academic Publishing.

34. Singh, P., Manser, P. \& Mestry, R. (2007). Importance of emotional intelligence in conceptualizing collegial leadership in education. South African Journal of Education, 27(3): 541-563.

35. Stein, S.J. \& Book, H.E. (2001). The EQ edge: Emotional intelligence and your success. New York: Stoddart.

36. Sternberg, R. (1996). Successful intelligence. New York: Simon \& Schuster.

37. Thilo, J.L. (2004). Emotional intelligence and leadership in the ASC. American Association of Ambulatory Surgery Centers. Retrieved from:

38. Van der Westhuizen, P.C. (1991). Effective educational management. Pretoria: HAUM Tertiary.

39. Yukl, G. (1998). Leadership in organisations. Saddle River: Prentice Hall. 